\title{
POLÍTICA DE DESPRECARIZAÇÃO DO TRABALHO EM SAÚDE EM UMA INSTITUIÇÃO FEDERAL DE C\&T: A EXPERIÊNCIA DE PROFESSORES E PESQUISADORES
}

\author{
POLICY FOR THE IMPROVEMENT OF THE WORK IN HEALTH AT A FEDERAL S\&T INSTITUTION: \\ THE EXPERIENCE OF PROFESSORS AND RESEARCHERS
}

\section{POLÍTICA DE DESPRECARIZACIÓN DEL TRABAJO EN SALUD EN UNA INSTITUCIÓN FEDERAL DE C\&T: LA EXPERIENCIA DE PROFESORES E INVESTIGADORES}

\author{
Priscila Matos Crisostomo da Silva ${ }^{1}$ \\ Kátia Reis de Souza ${ }^{2}$ \\ Liliane Reis Teixeira ${ }^{3}$
}

Resumo Este estudo teve como principal objetivo analisar a política de desprecarização do trabalho em saúde, em âmbito local, do ponto de vista de professores e pesquisadores. Para tal, efetuou-se um estudo de caráter qualitativo, elegendo-se como campo de investigação uma unidade técnico-científica de saúde localizada no estado do Rio de Janeiro. Para a coleta de dados, realizaram-se entrevistas individuais com dez participantes. No que concerne à análise dos materiais de campo, lançou-se mão da técnica de análise do discurso, chegando-se a cinco categorias empíricas principais de análise: precarização das relações humanas; transição do modelo de gestão institucional; intensificação do trabalho do professor e pesquisador; sofrimento e prazer no trabalho; e desprecarização do trabalho. Além disso, adotou-se como objeto de análise a política implementada pelo governo federal denominada DesprecarizaSUS. Os resultados mostraram que, do ângulo de interpretação do trabalho, a política de desprecarização deve alcançar um conjunto de ações políticas que não estão circunscritas apenas à esfera jurídica. A de maior relevância é a instituição, no plano local, de condições propícias para se superar a deterioração das relações humanas no trabalho geradas no âmbito do contexto neoliberal de gestão pública. Palavras-chave desprecarização; precarização; DesprecarizaSUS; serviço público; saúde do trabalhador.
Abstract The main objective of this article is to analyse the bettermen of work's policy at a work's local scope through the professors and researchers' perspective. To this end, we have chosen a qualitative study, and a scientific-technical health unit located in the State of Rio de Janeiro was elected such as a research field. For data collection, information was gathered through ten individual semi-structured interviews. Analysis of data was done through discourse analysis and five main empirical categories of analysis were found: precariousness of the human relations; transition to the institutional management model; professors and researchers' labor intensification; pleasure-suffering experiences at work; and, lastly, the bettermen of the work. In addition, we also adopted such as object of study a policy implemented by Brazilian federal government, whose name is Desprecarizasus. The results show that the bettermen of work's policy must reach a range of political actions, which are not restricted to the administrative level. In according to the professors and researchers' perspective it is essential to establish the conditions to overcome the deterioration of human relations at work generated by the neoliberal context of public administration.

Keywords bettermen of work; precariousness; DesprecarizaSUS; public service; work's health. 


\section{Introdução}

Nas últimas décadas, a globalização e a nova lógica capitalista de reestruturação produtiva deixaram marcas profundas na história do trabalho humano. Distingue-se nesse cenário a expansão do trabalho precarizado, temporário e terceirizado, que vem produzindo efeitos dramáticos na vida dos trabalhadores. Trata-se de formas de desregulamentação do trabalho que carecem da expansão de nosso quadro conceitual de análise (Druck e Franco, 2011; Antunes, 2003; Lacaz, 2007).

Antunes (2001) e Mészáros (2006) asseguram que a crise estrutural que abalou as economias capitalistas a partir dos anos 1970 contribuiu para o alastramento do ideário definido pelo neoliberalismo, que impôs fortemente a defesa da liberdade de mercado, ao mesmo tempo que restringiu a intervenção estatal na economia. Nesse contexto, a flexibilização do mercado encontrou terreno fértil para se desenvolver, pois ela dissolvia a rigidez das regras contratuais de trabalho, vista como empecilho à expansão do capital financeiro. Por conseguinte, foram colocados em prática ajustes estruturais consubstanciados em ações de diminuição da intervenção estatal, como enxugamento dos gastos públicos e privatização das empresas estatais, apenas para citar os que tiveram relação direta com o serviço público (Gomes, Silva e Sória, 2012; Costa, 2005). Tal cenário, marcado pela flexibilização do mercado de trabalho, suscitou prejuízos a conquistas históricas consolidadas pelos trabalhadores no que diz respeito às relações entre capital e trabalho.

Os efeitos provenientes dessas mudanças impactaram o Brasil nos anos 1990, pois nesse período o país adotou o pacote de medidas formulado pelo Consenso de Washington, cuja política visava promover o ajustamento macroeconômico dos países em desenvolvimento (Giannotti, 2007). Com isso, efetivou-se a adequação da política econômica do Estado nacional aos moldes do capital, fazendo valer a expressão “Estado mínimo subordinado ao mercado máximo" (Behring, 2001, p. 112).

Consequentemente, algumas providências foram tomadas a favor do capital para se atingir esse objetivo: ataque aos direitos trabalhistas, enfraquecimento dos sindicatos e investida aos servidores públicos. No que tange a essa categoria de trabalhadores, o governo Collor tomou medidas como o fechamento de órgãos públicos. Todavia, as restrições impostas pela legislação impediram que o ajuste dessa categoria fosse feito pela via da demissão sumária. Assim, a saída encontrada e viável foi a suspensão dos concursos públicos, pois o governo tratou o serviço público como problema fiscal (Gomes, Silva e Sória, 2012). Essa situação não teve grandes variações durante os governos dos presidentes Itamar Franco e Fernando Henrique Cardoso.

Quando Lula assumiu a presidência, encontrou o país submerso no momento designado como Pós-Consenso de Washington. Segundo Gomes, 
Silva e Sória (2012), um dos aspectos bem demarcado nesse governo foi a questão de tornar o Estado mais eficiente, inclusivo e equitativo, valorizando-se as estatais, que assumiriam a posição de impulsionadoras do desenvolvimento do país. Não obstante, atender a essa demanda exigia a resolução de algumas questões herdadas dos governos anteriores, como a referente aos trabalhadores com vínculos precários nas instituições públicas.

Inserida nesse ambiente, a instituição pública de ciência e tecnologia em saúde, escopo do estudo apresentado neste artigo, tinha em seu quadro funcional trabalhadores com vínculos precários atuando em diferentes funções, "incluindo serviços especializados e de caráter finalístico" (Fundação Oswaldo Cruz, 2004 , p. 3). A situação cresceu de tal forma que a estatística referente à distribuição da força de trabalho chegou a apresentar um quadro de servidores inferior ao quantitativo de trabalhadores terceirizados, conforme exposto no estudo de Araújo (2009). No intuito de regularizar os vínculos de trabalho e em consonância com a política do governo federal que começava a implementar o Programa Nacional de Desprecarização do Trabalho no Sistema Único de Saúde (SUS) (Brasil, 2006), a instituição encaminhou resoluções das suas instâncias participativas internas (Congresso Interno da Fiocruz) ao governo federal relativas à desprecarização dos vínculos de trabalho (Fundação Oswaldo Cruz, 2004), consubstanciadas principalmente na realização de concurso público.

O ponto que quisemos realçar no estudo aqui apresentado é que se, por um lado, o Estado colocou em prática a desprecarização do trabalho fundamentalmente pela realização de concurso público para provimento de vagas para funcionários efetivos, por outro, pelo ângulo do trabalho, existe um conjunto de problemas que persistem, configurando a necessidade de intervenções para que de fato se desprecarize o trabalho no serviço público. Desse modo, teve-se como objetivo principal do estudo analisar a política de desprecarização do trabalho em saúde, em âmbito local, do ponto de vista de professores e pesquisadores. Além disso, ao exame da literatura e da realidade, indagou-se a respeito da eficiência da política de desprecarização no âmbito local, sobretudo no que diz respeito às relações de trabalho. Buscou-se evidenciar a contradição existente entre a política de desprecarização de caráter nacional e a sua configuração na esfera local. Assim, formulou-se a seguinte pergunta norteadora de pesquisa: qual a perspectiva dos trabalhadores para que, de fato, se efetive uma política de desprecarização do trabalho no âmbito local?

\section{DesprecarizaSUS: Programa Nacional de Desprecarização do Trabalho no SUS}

Para apresentar os preceitos da política levada a efeito pelo governo federal de desprecarização do trabalho em saúde, lançamos mão de dois documentos 
do Ministério da Saúde (Brasil, 2005, 2006). De acordo com o conteúdo desses documentos, "o DesprecarizaSUS é uma estratégia de ação do governo federal cujo objetivo principal é a desprecarização dos vínculos de trabalho na saúde" (Brasil, 2006, p. 13).

Em ambos os textos sobressaem algumas asserções importantes de serem observadas: a desprecarização no âmbito do Estado é entendida como uma política de governo que busca a valorização do trabalhador; a noção nucleadora de trabalho precário relaciona-se, essencialmente, à ausência dos direitos sociais dos trabalhadores; o diálogo é adotado como estratégia política fundamental (por exemplo: Mesa Nacional de Negociação Permanente, que criou o Comitê Nacional de Desprecarização); o processo de desprecarização no âmbito federal deve empreender ações ao lado do Ministério Público e conselhos de saúde do país para que seja cumprido o que preconiza a Constituição Federal, especialmente no que se refere aos direitos sociais e ao ingresso ao serviço público via concurso.

Chama a atenção no referido documento a centralidade de algumas teses políticas: o caráter participativo do processo de sua formulação, que instituiu, em 2003, o Comitê Nacional Interinstitucional de Desprecarização do Trabalho no SUS; a articulação de diferentes setores governamentais para a execução das ações de desprecarização; e finalmente a defesa e valorização do servidor público com ênfase nos aspectos de humanização da gestão do trabalho em saúde. Além disso, cabe mencionar que nos documentos em questão se reconhece o intenso processo de precarização ocorrido no setor saúde no Brasil como consequência da reforma de Estado dos anos 1990. Nos termos do documento, admite-se que há, no âmbito do Ministério da Saúde, um expressivo contingente de trabalhadores que se encontram em franca situação de insegurança trabalhista e social, sendo tal situação uma violação às normas vigentes do direito administrativo e do trabalho.

No que tange aos estudos a respeito dessa política, constata-se a existência de pontos fundamentais e controversos. Segundo Rézio e Oliveira (2010), embora o Ministério da Saúde tenha criado o DesprecarizaSUS adotando uma política de valorização do trabalhador, com o intuito de promover contratos efetivos, melhorias salariais e políticas de humanização, nota-se que na realidade ainda prevalecem contratos temporários, como forma de vínculo de trabalho precário na área de saúde. Ressaltemos ainda, como lembram Pierantoni e colaboradores (2008), que não se observa a capilaridade dessa política, tanto pelo desconhecimento desse programa quanto pelo fato de que, dentre os que alegam conhecê-lo, dele não participam. Portanto, os autores apontam para os limites da política do DesprecarizaSUS, a qual não chegou a alcançar o interior do sistema de saúde.

Contudo, a questão que nos pareceu relevante foi observada por Murofuse e colaboradores (2009), segundo a qual a política levada a efeito pelo 
DesprecarizaSUS tem como um de seus desafios ampliar o consenso sobre o conceito de trabalho precário, indo além da pauta reivindicatória, como ausência de direitos trabalhistas e previdenciários legais, decorrentes de terceirizações indiscriminadas, contratos irregulares via cooperativas e, principalmente, ausência de concurso público. Concorda-se com Nogueira (2006) quando afirma que a melhor definição para o DesprecarizaSUS é aquela segundo a qual ele é compreendido como política específica de regularização dos vínculos de trabalho. Trata-se, portanto, de uma política de regularização jurídico-administrativa, que tem por objetivo fazer valer a norma legal de trabalho na administração pública, começando pela forma de ingresso por meio de concurso público.

\section{Referencial teórico: precarização do trabalho}

Partiu-se do pressuposto teórico segundo o qual a precarização do trabalho é concebida como peça integrante da atual composição estrutural do capital e tem como particularidade histórica a deterioração das relações sociais e pessoais do trabalho (Alves, 2013). Contudo, não se trata de um conceito simples, tampouco unívoco. Em verdade, reconhece-se que existem variantes no sentido de precarização quando se levam em consideração, sobretudo, as diversas situações nos locais de trabalho.

Nogueira, Baraldi e Rodrigues (2005) referem-se à dificuldade em se definir o conceito de precarização. Todavia, a despeito de sua complexidade, identificam um núcleo comum de interpretação presente na literatura. Segundo os autores, esse conceito, também definido como sinônimo de precariedade e informalidade, envolve três sentidos recursivos importantes de serem observados: desproteção social do trabalho, extensão temporal dos contratos e vulnerabilidade da condição de emprego do trabalhador em determinados setores da economia.

Quanto ao primeiro aspecto referido no estudo de Nogueira, Baraldi e Rodrigues (2005) - desproteção social do trabalho -, estariam incluídas aquelas situações de perdas referentes aos direitos sociais adquiridos historicamente pelos trabalhadores. Nessa perspectiva, compreende-se que o trabalho se realiza desprovido de benefícios clássicos e garantias aos quais no passado os trabalhadores tinham acesso, como previdência social, seguro para acidentes de trabalho, licenças, férias remuneradas, aposentadoria, recebimento de décimo terceiro, entre outros. Nesse ponto, cabe mencionar que Castel (2003) chama a atenção para o fato de a precarização do trabalho ser um processo universal e central, ordenado pelas novas exigências econômicas da evolução do capitalismo moderno, inclusive modificando os regimes de trabalho em áreas onde a estabilidade seria uma designação da lei 
(como o serviço público); trata-se da 'desestabilização dos estáveis'. Ademais, a ideia de "metamorfose do trabalho" (Castel, 2003, p. 28) traduz de forma inédita a perenidade de o atual modo de organização do trabalho se estruturar, aprofundando a desproteção e a vulnerabilidade dos trabalhadores.

A segunda especificidade diz respeito à extensão temporal dos contratos, que apreende as formas de contrato por tempo determinado como precárias, uma vez que criam um sentimento de instabilidade no trabalhador (Nogueira, Baraldi e Rodrigues, 2005). Segundo Castel (2003), a expressão 'interino permanente' não é um mero jogo de palavras, mas uma face da incerteza do amanhã do trabalhador em relação a sua permanente insegurança no trabalho.

O terceiro ponto referido no estudo de Nogueira, Baraldi e Rodrigues (2005) refere-se à vulnerabilidade da condição de emprego do trabalhador. Trata-se de um conceito adotado pela Organização Internacional do Trabalho (OIT), que define a vulnerabilidade do emprego do trabalhador como resultado da falta de vigor e competitividade de certos setores geradores de emprego. Por este motivo, tais empregos estariam sob a constante ameaça de serem extintos, colocando os trabalhadores em situação de vulnerabilidade. Castel (2003) faz referência a um sentido mais amplo de vulnerabilidade, que é o de 'vulnerabilidade social', cuja ideia refere-se a uma zona de total instabilidade do viver que conjuga a precariedade do trabalho com a fragilidade dos suportes de proximidade entre as pessoas, suscitando o chamado 'individualismo negativo'.

Seja como for, as interpretações relativas ao conceito de precarização convergem para um mesmo ponto, segundo o qual a precarização se constitui na implicação mais forte da flexibilização laboral por meio, principalmente, da adoção de normas jurídicas menos rígidas que regem o contrato de trabalho, demandando a adequação do trabalho aos novos parâmetros impostos pelo capital (Castel, 2003; Antunes, 2001). Como resultado, a precarização, entendida como "processo social constituído pela ampliação e institucionalização da instabilidade e da insegurança", contingenciou o trabalho às necessidades do mercado (Mony e Druck, 2007, p. 30). As consequências dessa implicação são exatamente as formas de desumanização do trabalho.

Em termos práticos, as consequências desse processo de precarização do trabalho reverberam na flexibilização da legislação brasileira que atinge as relações contratuais de trabalho, interferindo nas condições em que o trabalho deve ser exercido. Ao analisarem as formas de precarização do trabalho no Brasil e na França, Mony e Druck (2007) observam o intenso processo de flexibilização existente no Brasil, o que demanda a realização de novos estudos para aprofundamento da questão. Do mesmo modo, consoante Alves (2009), torna-se necessário apreender as experiências de precarização 
do trabalho como novas questões a serem enfrentadas na era de reestruturação capitalista no país.

Assim, compreende-se como relevante o desenvolvimento de estudos específicos que possibilitem conhecer as particularidades do processo de precarização do trabalho, em nível local, do ponto de vista dos próprios trabalhadores.

\section{Metodologia}

O estudo aqui apresentado teve caráter qualitativo, filiando-se do ponto de vista epistemológico a uma tradição dos estudos interpretativos, o que implica assumir uma posição crítica diante dos textos da realidade (Bauer, Gaskell e Allum, 2008). De acordo com Gill (2008), nessa perspectiva teórico-metodológica existe a convicção de que o conhecimento é socialmente construído e não dado, devendo ainda suscitar ações práticas como parte do processo de produção de conhecimento. Ademais, o aporte metodológico adotado apoiou-se nos pressupostos do campo da saúde do trabalhador, e o principal aspecto diz respeito ao reconhecimento dos trabalhadores como sujeitos do conhecimento e portadores da experiência do trabalho (Oddone, 1986; Lacaz, 2007).

Quanto aos procedimentos de pesquisa, o critério utilizado para a escolha de uma instituição científica de saúde no Rio de Janeiro como campo de investigação considerou o fato de esta possuir em seu quadro funcional uma grande quantidade de servidores com vínculo precário de trabalho (contratos temporários) - parte desses trabalhadores foi incorporada ao quadro de servidores estáveis, seguindo a política de desprecarização implementada pelo governo federal.

A opção pela categoria de pesquisadores e professores sinalizou para o fato de que a precarização não atinge apenas trabalhadores de menor qualificação, mas "hoje, atinge dramaticamente os trabalhadores com elevada qualificação, tanto nos países desenvolvidos quanto nos subdesenvolvidos" (Nogueira, Baraldi e Rodrigues, 2005, p. 82).

Para a seleção dos participantes, adotou-se, como critério de inclusão, servidores que passaram pela situação de vínculo precário de trabalho com posterior ingresso ao quadro de funcionários estáveis por meio de concurso público; e quanto ao critério de exclusão, servidores que ainda viviam a situação de vínculo precário de trabalho. Selecionaram-se 33 servidores elegíveis, e o tamanho da amostra foi definido, a priori, em torno de dez participantes. A rigor, o alto grau de representatividade não é relevante nos estudos de abordagem qualitativa, pois a preocupação é com o aprofundamento das questões por meio das significações que os participantes trarão durante a entrevista, como assinalado por Goldenberg (2001) e Turato (2005). 
Obteve-se a resposta afirmativa de dez profissionais. Do restante, a grande maioria não respondeu ao convite para participação na pesquisa. Para a entrevista, utilizou-se um roteiro semiestruturado, composto de oito perguntas abertas que abordavam o período anterior e posterior ao concurso público realizado.

Quanto à análise dos dados, adotou-se a técnica de análise do discurso seguindo o enfoque proposto por Gill (2008) e Minayo (2010). Tratou-se então de ler e reler as transcrições das entrevistas até que nos familiarizássemos com elas, chegando às categorias de análise. De acordo com Minayo (2010), buscou-se a reflexão crítica por intermédio de um processo de problematização e significação do texto analisado. Gill (2008) pondera que a imersão nos materiais de campo possibilita a codificação, que é determinada pelas questões de interesse do estudo.

A rigor, realizaram-se dois procedimentos classificatórios dos materiais advindos das entrevistas: no primeiro, agruparam-se os trechos das entrevistas por frequência e por similaridade de sentidos, ou seja, reuniram-se aqueles excertos de entrevistas que apareciam recursivamente e apresentavam semelhanças. Dessa junção de trechos de falas foram formados os núcleos de sentido. Quanto ao segundo procedimento, organizaram-se tais núcleos - quer dizer, os agrupamentos das passagens de entrevistas - com títulos representativos que se constituíram em categorias empíricas de análise: precarização das relações humanas; transição do modelo de gestão institucional; intensificação do trabalho do professor e pesquisador; sofrimento e prazer no trabalho; e desprecarização do trabalho.

O projeto de pesquisa foi aprovado pelo Comitê de Ética em Pesquisa da Escola Nacional de Saúde Pública Sergio Arouca da Fundação Oswaldo Cruz (Ensp/Fiocruz) com a inscrição CAAE n. 02429412.2.0000.5240.

\section{Resultados e discussão}

\section{Precarização das relações humanas}

Quando eu era bolsista, por mais que fossem frágeis os vínculos, dentro do laboratório a gente tinha uma certa solidariedade ou um certo espírito de equipe ou de possibilidades de exercer o nosso trabalho. (...) Hoje, o nosso laboratório é um laboratório que, talvez, uma das unidades da Fiocruz que mais tiveram pessoas que pediram pra sair. Hoje, das dez pessoas que entraram, nove saíram. (...) Você desprecarizou. E as relações? Você desprecariza como? (Servidor 1).

Mas você tem um outro tipo de precarização. Você tem os direitos garantidos, mas a relação de trabalho é precária (...) Na verdade, ela [a política de desprecarização] só dá conta do nível mais primário da precarização, mais primitivo, mais inicial (Servidor 10). 
Durante as entrevistas, sobressaiu a ideia de fragilidade dos vínculos de proximidade e das relações de trabalho como uma forma de precarização laboral. Observou-se que, segundo os participantes, alcançar a estabilidade e os direitos no trabalho foi importante, contudo eles queixaram-se da ausência de laços de solidariedade e cooperação no cotidiano de trabalho como aspectos que proporcionam satisfação. Houve na interpretação dos entrevistados um sentido de precarização que ultrapassava o significado preconizado pela política de desprecarização, o qual dizia respeito à deterioração das relações humanas e sociais.

Na linha de interpretação de Sennett (2002), existem consequências nas relações de trabalho suscitadas pelas novas formas de organização do capitalismo. Este autor evidencia o fato segundo o qual a precarização do trabalho no 'novo capitalismo' tem modificado os valores e o modo de ser das pessoas, suscitando desigualdades e diferenças nas relações de trabalho. Sennett (2004, p. 78) chama a atenção para a importância da prática do respeito mútuo e inclusivo no trabalho, rejeitando-se a acomodação à situação de desigualdade, pois "existe um abismo entre esperar agir bem em relação aos outros e agir bem de fato". O que estava faltando, nos termos dos entrevistados, eram precisamente relações mútuas de respeito no trabalho, já que, embora se tivessem alcançado as mesmas condições entre os trabalhadores no que dizia respeito ao seu caráter jurídico, constatou-se que as relações sociais estavam impregnadas pelo desrespeito ao diferente (Sennett, 2004).

Consideremos ainda que, de acordo com Schwartz e Durrive (2007), cada local de trabalho é único, porquanto os variados espaços de trabalho são atravessados por culturas políticas e relações interpessoais diversas. De acordo com a perspectiva dos autores, é imprescindível ir ver de perto o que acontece em cada local de trabalho. No caso do estudo aqui apresentado, os trabalhadores entrevistados, tomando por base os problemas de relações interpessoais enfrentados no trabalho, ratificaram a acepção de precarização que inclui o aspecto referente ao enfraquecimento dos laços de proximidade e solidariedade no trabalho.

Eu não vejo a desprecarização apenas vinculada à forma de contratação, mas em relação a processos de trabalho. Eu acho que, às vezes, eles são colocados de forma que a gente pode estar qualificando como precárias (Servidor 7).

Nas entrevistas, encontramos ainda o sentido consoante o qual a desprecarização deveria alcançar, como proposta política, os processos de trabalho no âmbito local. Para Bosi (2007), embora os estudos sobre precarização sejam numerosos, de modo geral limitam-se à dimensão da flexibilização das relações contratuais de trabalho, discutindo de maneira superficial as transformações experimentadas no cotidiano do trabalho. Fato é que existia um 
descompasso entre as ações da política de desprecarização implementadas no nível estrutural e a existente no nível local, pois se por um lado instalaram-se novas regras de regulação do trabalho (aspecto macro), por outro verificaram-se no lugar onde acontecia a atividade de trabalho peculiaridades como conflitos e tensões interpessoais que eram, na experiência dos entrevistados, os reais elementos de configuração do trabalho precarizado.

No que tange aos processos de trabalho, observe-se que, como lembra Harvey (2011), as relações humanas - envolvidas nos processos de trabalho são sempre assuntos complexos. "No processo de trabalho o trabalhador é o agente criador" (Harvey, 2011, p. 88), podendo se recusar a cooperar. O tema das relações humanas no âmbito laboral diz respeito, de forma particular, ao local de trabalho e às micropolíticas de gestão (Souza e Rozemberg, 2013). Desse modo, modificar as relações de trabalho de maneira a se suscitar solidariedade significa promover, por meio da governança institucional, um debate de valores, tendo o próprio trabalho - e a sua organização como centro do diálogo, incluindo aqueles trabalhadores que ainda permanecem com vínculo precário de trabalho.

Segundo Dejours e Abdoucheli (2007), o desafio imposto à organização do trabalho situa-se no hiato existente entre a organização prescrita e a organização real do trabalho, pois a primeira pode ser apreendida como o modo operatório, ou seja, divisão de tarefas, repartição das responsabilidades, hierarquia e comando - ao passo que a segunda se constitui, em linhas gerais, no produto das relações sociais partindo-se da premissa de que seus ajustes decorrem de conflitos técnicos, sociais e psicoafetivos. Portanto, ao se tomar por base a análise da organização real do trabalho, verificou-se que a concepção de desprecarização deve também considerar a organização do trabalho e suas configurações locais.

\section{Transição do modelo de gestão institucional}

$\mathrm{Eu}$, por exemplo, não sei se concordo completamente com o que a Fiocruz tá virando. Essa coisa do complexo da saúde, essa economização da nossa inserção dentro da Reforma Sanitária, essa cara muito fábrica (Servidor 5).

Houve também aquilo que eu considero uma quebra da Fiocruz com os compromissos da Reforma Sanitária (...) a relação entre capital e trabalho, ela vem sendo naturalizada (Servidor 8).

Nas entrevistas, foram recorrentes as referências à atual polêmica existente no âmbito do setor saúde no Brasil, que tem por base os conceitos de inovação tecnológica em saúde e de complexo médico-industrial (CMI) ou complexo médico-financeiro (CMF). Sem entrar no mérito do debate que o 
problema exige, a questão principal no âmbito da controvérsia acadêmica e política resume-se ao antagonismo entre interesses econômicos e valores sociais (Mendonça e Camargo Jr., 2012).

De acordo com os entrevistados, a instituição passava por um processo de 'transformação', 'transição' e 'descontinuidade' em relação aos ideais do movimento sanitarista, base da concepção do SUS. Nesse sentido, Oliveira e Galvão (2007) ressaltam que a meta das instituições públicas é buscar o aperfeiçoamento das práticas de gestão para atender às demandas da sociedade e para o cumprimento das políticas públicas. Por sua vez, Gadelha (2003) afirma que não há como pensar em políticas públicas sem que se reconheça a natureza produtiva da área da saúde, pois somente assim será possível a busca de meios eficazes para que as finalidades sociais sejam atingidas nos marcos desse sistema. Todavia, ao se retomar a fala de um dos entrevistados, o que se observou foi que "a relação entre capital e trabalho vem sendo naturalizada", distanciando-se, portanto, dos compromissos preconizados pelo movimento de reforma sanitária.

Em consonância com essas reflexões, Santos e Passos (2010) entendem que esse padrão de 'inovações' substitui o cuidado e a assistência à saúde por um novo padrão corporativo de prestação de serviços de saúde, baseado numa racionalidade empresarial que faz com que o processo de transição das instituições de saúde seja permeado por contrassensos. Por conseguinte, participamos, no estudo aqui apresentado, da interrogação feita por Mendonça e Camargo Jr. (2012, p. 221): “como levar em conta a lógica econômica em um setor que deveria se pautar pelo atendimento das necessidades das pessoas por intermédio de uma prestação de serviços de qualidade, de modo integralizado e universalizado?" Decerto, constatou-se que a política institucional de desprecarização foi desenvolvida num momento em que emergia um conjunto de outras políticas que, no ângulo de compreensão dos participantes deste estudo, deveriam valorizar a dimensão social e humana do setor saúde. Ao contrário, verificou-se que as denominadas transformações no modo da governança pública institucional vêm gerando o aprofundamento da precarização das relações humanas e sociais do trabalho.

\section{Intensificação do trabalho do professor/pesquisador}

Eu desempenhei minhas funções tanto na pesquisa, aqui dentro (...), quanto de docente e coordenação de curso. (...) A forma de distribuição do trabalho aqui é de um taylorismo, fordismo absurdo (Servidor 1).

Aqui é uma unidade em que a gente trabalha muito. A gente tem muita atividade de sala de aula, tem muito trabalho de organização dos cursos. E a gente sempre teve como objetivo fazer com que as condições de trabalho pudessem contar com 
trabalhos produzidos pelo próprio corpo docente, o que acaba fazendo com que a gente tenha um vínculo com a pesquisa muito grande (Servidor 2).

O grande número de funções acumuladas pelos professores e pesquisadores transpareceu em diversos discursos dos entrevistados, evidenciando o que a literatura afirma a respeito da intensificação do trabalho docente como marca da nova organização do trabalho na educação. Desse modo, inferimos que a multiplicidade de atividades assumida pelos docentes contribui para a constatação do quadro de intensificação do trabalho (Lemos, 2011; Garcia e Anadon, 2009; Maués, 2010; Bosi, 2007), o que acaba por se constituir em um dos desafios apresentados para essa categoria de trabalhadores, como sinalizado por Lelis (2012).

Oliveira (2004), ao discutir as atuais condições de trabalho dos docentes de escolas públicas brasileiras, ressalta como consequência das reformas educacionais mais recentes o fato de que esses profissionais têm assumido funções que estão além de sua formação e suas atribuições, resultando no que a autora denomina de 'desprofissionalização docente'. De acordo com esse autor, o trabalho docente não está circunscrito apenas às atividades em sala de aula; ele compreende a gestão da escola no que concerne à dedicação dos professores ao planejamento, à elaboração de projetos, à discussão coletiva do currículo e da avaliação. Trata-se de um processo de sobrecarga de trabalho que vem aumentando.

Interpretação similar é compartilhada por Assunção e Oliveira (2009), que acrescentam que a intensificação, além de comprometer a saúde desses profissionais, pode pôr em risco a qualidade da educação e os fins últimos da escola. Todavia, o interessante é que essas novas (e muitas) atribuições, apresentadas como novidade ou inovação, muitas vezes são tomadas como algo natural pelos docentes.

Verifica-se, então, que a intensificação laboral referente ao trabalho docente é consequência das políticas públicas educacionais mais amplas, de cunho neoliberal e de caráter produtivista (Oliveira, 2004). Nessa linha de interpretação, sobressai a exigência por quantidade de publicação acadêmica, distanciando-se da concepção de ciência como construção coletiva, resultado de colaboração e cooperação, aprendizagem e reflexão, abrindo-se espaço para a competição estimulada por formas de avaliação individual (Freitas, 2011). É digna de menção a observação de Mendonça (2014), segundo a qual o processo de precarização e de sobrecarga do trabalho dos professores ante a nova organização do trabalho docente vem ocasionando um grande sofrimento psíquico a esses trabalhadores. Assim, os docentes começam a viver sob a égide de um paradoxo angustiante: a relação de dor e prazer do ofício. 


\section{Sofrimento e prazer no trabalho}

Quando você não faz parte do grupo, você é colocada de lado, então isso me causou sofrimento durante um tempo. Me causou sofrimento e eu fazia análise. Hoje eu posso dizer que o sofrimento, ele é superado. (...) E eu vou te falar outra coisa: se hoje eu não estivesse com o meu grande projeto, que é o doutorado, (...) eu estaria dentro do pior trabalho possível. Do pior trabalho possível (Servidor 1).

Eu acho que o trabalho nas instituições públicas é um trabalho muito tenso porque a questão da exacerbação das relações pessoais, as coisas que não são ditas, que não são escritas, mas que na verdade são sentidas, ela é muito intensa no serviço público. (...) eu acho que isso traz muita tensão, muita frustração (Servidor 5).

Constatou-se durante as entrevistas que as relações laborais têm efeitos na vida desses trabalhadores, principalmente no plano da subjetividade. Os participantes mencionaram situações de conflito e ambientes tensos que resultaram em sofrimento e ressentimentos. Com efeito, na linha de compreensão da psicodinâmica, as relações intersubjetivas no trabalho são o foco fundamental de análise e intervenção (Dejours, 2008). Para o autor, não observar a dimensão subjetiva do trabalho pode levar a consequências nefastas para a saúde mental e somática dos trabalhadores.

Encontramos em Dejours $(1980,2008)$ a ideia de que o contexto de trabalho tem impactos sobre a vida dos trabalhadores, mas que os trabalhadores são capazes de construir sistemas defensivos individuais e coletivos de modo a se defenderem dos efeitos patogênicos do trabalho. Ao produzirem prazer, os sujeitos conseguem se manter no campo da normalidade. Essa normalidade, considerada um enigma pelo autor, ocorre numa tentativa de equilíbrio instável e precário em relação aos efeitos nocivos do trabalho. Trata-se de uma normalidade que se dá como resultado de estratégias complexas e dinâmicas, as quais precisam ser mais bem examinadas em suas configurações locais.

Eu tenho satisfação no trabalho porque eu tenho satisfação de pensar o meu trabalho. (...) isso se reflete nos alunos (Servidor 3).

O trabalho é muito importante pra mim e me faz feliz. (...) Eu tive o privilégio de poder escolher. Eu não estou na saúde pública por acaso. Eu estou na saúde pública por uma escolha. Eu considero isso um privilégio no contexto social brasileiro (Servidor 4).

Embora tenha se observado que vários relatos apontaram para a intensificação do trabalho docente e o sofrimento decorrente de situações de 
conflitos no ambiente de trabalho, constatou-se que, ao lado do sofrimento, convivia-se com a satisfação e o prazer. Sobressaiu nos depoimentos o sentido de realização pelo trabalho no que diz respeito a ser uma atividade permanentemente reflexiva. Durand, Saury e Veyrunes (2005) constataram, com base em levantamento sobre a percepção de docentes da universidade de Oriente (Venezuela) a respeito de seu trabalho, que os aspectos de satisfação estavam relacionados com algumas características próprias do labor docente, entre elas a autonomia no trabalho, a liberdade para expressar ideias, a oportunidade de contribuir para o conhecimento e o prestígio de ser um acadêmico.

Na reconstrução da questão concernente à satisfação no trabalho, Marqueze e Moreno (2005), ao realizarem uma revisão sobre esse tema, concluem que o processo de satisfação no trabalho resulta da complexa e dinâmica interação das condições gerais de vida, das relações de trabalho, do processo de trabalho e do controle que os trabalhadores têm sobre essas condições.

\section{Desprecarização do trabalho}

O laboratório se tornou hoje essa megaestrutura que tem 33 pessoas. Destas, deve ter hoje uns oito servidores só. Olha a desprecarização que houve, nenhuma (Servidor 1).

(...) dois terços dos profissionais da escola eram precarizados. (...) É muito difícil depois que precarizou tanto fazer mudanças tão radicais nos processos, porque você acaba mexendo na cultura da instituição. Você corre o risco de perder trabalhos que estavam sendo construídos (Servidor 2).

Tem gente aqui que tem mais de dez, vinte anos nessa escola como bolsista. (...) Tem determinados laboratórios que eles têm receio de pedir um número maior de vagas porque ainda têm muitos bolsistas, e isso desorganiza a equipe (Servidor 6).

As falas dos entrevistados evidenciaram dois tópicos importantes para o processo de desprecarização do trabalho no serviço público. O primeiro diz respeito ao fato de que ainda existem muitos trabalhadores em situação de vínculo precário de trabalho, ou seja, constatou-se um quadro com muitas diferenças e desigualdades de vínculos que se refletiam nas relações interpessoais e coletivas de trabalho. Quanto ao segundo aspecto, refere-se à alusão segundo a qual o ingresso de novos trabalhadores, via concurso, 'desorganiza a equipe'. Observe-se que, conforme visto, o governo federal (Brasil, 2005) apreende o conceito de precariedade como relacionado a alguma irregularidade, isto é: a precariedade diz respeito à situação de desobediência às normas vigentes do direito administrativo e do direito do trabalho. 
Além disso, na administração pública a admissão de trabalhadores sem concurso se constitui numa forma irregular de ingresso, o que significa dizer que o vínculo desses trabalhadores com o Estado não tem base legal. Para a concessão de bolsas de trabalho há respaldo legal, desde que sejam cumpridos os requisitos e condições impostos pelas agências de fomento à pesquisa. Todavia, quando as bolsas se constituem em instrumentos para a manutenção da força de trabalho, elas se inserem no que se denomina 'trabalho precário'. O documento (Brasil, 2005) ainda acentua que a fragilidade dessas modalidades de contratação acaba por comprometer a dedicação desses profissionais em razão da instabilidade do vínculo, conforme referido nas entrevistas.

Costa e Tambellini (2009) destacam a ideia de 'visibilidade dos escondidos' ao analisarem as cooperativas de trabalho que prestam serviço numa unidade pública federal de saúde. Os autores constataram que o ingresso de trabalhadores nesse setor, em face de um contexto que restringia a inserção de trabalhadores via concurso, efetivou-se por meio de formas precárias de contratação. Alguns aspectos observados por esses autores se assemelham aos dados encontrados no estudo aqui apresentado. Ambos destacaram que a inserção de novos trabalhadores, por meio de concurso, poderia interferir na substituição dos antigos com prejuízo da continuidade dos trabalhos.

Eu considerava o meu trabalho mais precarizado (...) do que aqui porque apesar de ser bolsista daqui, o salário não ser essas coisas, eu sentia um envolvimento com a escola (Servidor 3).

Eu acho que na Fiocruz, mesmo quem tem o vínculo de trabalho precário, não pode dizer que tenha condições precárias de trabalho. Eu acho que a Fiocruz é uma instituição (...) que dá condições de trabalho bastante satisfatórias em termos de segurança no trabalho, acomodações físicas, tecnologias, bibliotecas (Servidor 5).

No sentido atribuído pelos trabalhadores, a precarização do trabalho significa, em primeiro plano, a deterioração das relações pessoais de trabalho, que gera insatisfação e sofrimento. Por conseguinte, desprecarizar significa gerar condições favoráveis para o engajamento das pessoas no coletivo de trabalho e proporcionar condições dignas (físicas e materiais) de trabalho.

Ao adotar o ângulo de compreensão do trabalho, no âmbito real e cotidiano, Alves (2013) chama a atenção para o total esvaziamento dos indivíduos e suas relações no atual modo de produção. De acordo com o autor, há um completo estranhamento das pessoas, consigo mesmas e entre si. A solução necessária seria propiciar espaços e processos democráticos no trabalho. Decerto, as diversas interferências na vida laboral - numa instituição 
onde ainda prevalecem os vínculos precários de trabalho - suscitam contradições que não são facilmente perceptíveis como estranhas ao trabalho, necessitando de distanciamento crítico e diálogo coletivo e participativo a fim de serem superadas. Desse modo, conforme preconiza a política de humanização na gestão do trabalho em saúde (Brasil, 2005), deve-se reconhecer a importância dos espaços de discussão e reflexão em que se valorizem os diferentes saberes e a dimensão subjetiva e social do trabalho em saúde.

\section{Considerações finais}

Os dados apresentados e discutidos neste artigo nos levaram a concluir que, primeiramente, a implementação de uma política cuja finalidade é desprecarizar o trabalho no serviço público, principalmente por meio da realização de concursos, de fato representa uma iniciativa crucial para a democratização das formas de acesso aos serviços do Estado e o cumprimento dos preceitos constitucionais. A estabilidade do vínculo laboral proporciona, inegavelmente, condições concretas e simbólicas para que seus servidores cumpram plenamente o papel de mediadores entre Estado e sociedade.

Os resultados encontrados confirmaram e ampliaram o que mostram outros estudos (Machado e Koster, 2011; Jorge et al., 2007; Silva, 2006; Nogueira, Baraldi e Rodrigues, 2005) a respeito de aspectos que contribuem para a desprecarização do trabalho: mudar os processos e a organização de trabalho com a participação ativa dos trabalhadores; reconhecer que os impactos das reformas administrativas no setor saúde criaram obstáculos difíceis de serem superados em curto espaço de tempo e que, portanto, a eficácia da política de desprecarização necessitará de um vigoroso esforço integrado dos diversos segmentos sociais; e, por fim, admitir que existem limites nos conceitos de precarização e desprecarização do trabalho, de acordo com os pressupostos de natureza jurídica, que precisam ser muito bem elucidados, levando-se em consideração o ângulo de compreensão do próprio trabalho.

Gomez e Thedim-Costa (1999), ao analisarem o tema da precarização do trabalho no Brasil, fazem referência à ideia de se estabelecer um novo 'contrato social', negociado de forma ampla com todos os segmentos da sociedade civil. Nessa visão, prepondera o modelo de um Estado normativo e atuante no sentido da regulação das políticas de proteção social. Com efeito, parece acertada a posição de Castel (2003), de acordo com a qual o Estado é insubstituível na sua função fundamental de governar a favor da questão social. O desafio parece estar na construção de um Estado social sólido, que não se submeta às exigências da economia de um mercado globalizado e que garanta a universalização dessa política. 
Decerto, a constatação de um conjunto de dificuldades no âmbito estrutural - e que parecem distantes de serem solucionadas - nos levou a refletir sobre a possibilidade de se criarem, no plano local, as condições necessárias para se instituir a desprecarização do trabalho, principalmente por meio do estímulo de novas relações sociais e de vínculos de proximidade, como a criação de espaços democráticos de diálogo sobre a relação entre o trabalho e a saúde - conforme indicação tanto da Política Nacional de Humanização (Brasil, 2005) quanto da Política Nacional de Saúde do Trabalhador e da Trabalhadora (Brasil, 2012), com a organização de comissões de saúde do trabalhador por locais de trabalho (com o apoio dos gestores). Assim se responderia, em parte, à pergunta feita por um dos participantes da pesquisa: "Sob o ponto de vista do vínculo, você desprecarizou o trabalho; e as relações, você desprecariza como?"

As indagações e reflexões nos levaram a constatar que ainda temos um longo caminho a percorrer para que, de fato, a desprecarização do trabalho na ótica do trabalhador se efetive nas instituições públicas, transcendendo a esfera meramente jurídico-administrativa. Acreditamos que as pistas deixadas pelos participantes da pesquisa concederam elementos concretos que podem contribuir para a ampliação desse conceito e das formas de ação dessa política, sobretudo no que diz respeito aos locais de trabalho.

\section{Colaboradoras}

Priscila Matos Crisostomo da Silva participou da concepção do estudo, da pesquisa de campo, da análise dos dados e redação do artigo; Katia Reis de Souza foi coorientadora do estudo, participou da análise dos dados, redação do artigo e aprovação da versão final do manuscrito; Liliane Reis Teixeira foi orientadora do estudo, participou da análise dos dados, redação do artigo e aprovação da versão final do manuscrito. 
Resumen Este estudio tuvo como principal objetivo analizar la política de desprecarización del trabajo en salud, en el ámbito local, desde el punto de vista de profesores e investigadores. Con ese fin, se realizó un estudio de carácter cualitativo, eligiendo como campo de investigación una unidad técnica y científica de salud, ubicada en el estado de Río de Janeiro, Brasil. Para la recolección de datos se realizaron entrevistas individuales con diez participantes. En lo que concierne al análisis de los materiales de campo, se utilizó la técnica de análisis del discurso, llegándose a cinco categorías empíricas principales de análisis: precarización de las relaciones humanas; transición del modelo de gestión institucional; intensificación del trabajo del profesor e investigador; sufrimiento y placer en el trabajo; desprecarización del trabajo. Además de ello, se adoptó como objeto de análisis la política implementada por el gobierno federal denominada DesprecarizaSUS. Los resultados mostraron que, del ángulo de interpretación del trabajo, la política de desprecarización debe alcanzar un conjunto de acciones políticas que no se circunscriben apenas a la esfera jurídica, siendo la de mayor relevancia la institución, en el plano local, de condiciones propicias para superar el deterioro de las relaciones humanas en el trabajo generadas en el ámbito del contexto neoliberal de gestión pública.

Palabras clave desprecarización; precarización; DesprecarizaSUS; servicios públicos; salud del trabajador.

\section{Notas}

1 Fundação Oswaldo Cruz, Escola Nacional de Saúde Pública Sergio Arouca, Rio de Janeiro, RJ, Brasil.

<priscilafurs@yahoo.com.br>

Correspondência: Fundação Oswaldo Cruz, Escola Nacional de Saúde Pública Sergio Arouca, Centro de Estudos da Saúde do Trabalhador e Ecologia Humana, Rua Leopoldo Bulhões, 1.480, Manguinhos, CEP 21041-210, Rio de Janeiro, RJ, Brasil.

2 Fundação Oswaldo Cruz, Escola Nacional de Saúde Pública Sergio Arouca, Centro de Estudos da Saúde do Trabalhador e Ecologia Humana, Rio de Janeiro, RJ, Brasil.

$<$ katreis@ensp.fiocruz.br>

3 Fundação Oswaldo Cruz, Escola Nacional de Saúde Pública Sergio Arouca, Centro de Estudos da Saúde do Trabalhador e Ecologia Humana, Rio de Janeiro, RJ, Brasil.

<lilianeteixeira@ensp.fiocruz.br> 


\section{Referências}

ALVES, Giovanni. Trabalho e reestruturação produtiva no Brasil neoliberal: precarização do trabalho e redundância salarial. Revista Katálysis, Florianópolis, v. 12, n. 2, p. 188-197, 2009.

ALVES, Giovanni. Dimensões da precarização do trabalho: ensaios de sociologia do trabalho. Bauru: Canal 6, 2013.

ANTUNES, Ricardo. Trabalho e precarização numa ordem neoliberal. In: GENTILI, Pablo; FRIGOTTO, Gaudêncio (orgs.). A cidadania negada: políticas de exclusão na educação e no trabalho. 2. ed. São Paulo: Cortez, 2001. p. 35-48.

ANTUNES, Ricardo. O caráter polissêmico e multifacetado do mundo do trabalho. Trabalho, Educação e Saúde, Rio de Janeiro, v. 1, n. 2, p. 53-61, 2003.

ARAÚJO, Ana L. D. A capacitação de recursos humanos em uma instituição de C\&T em saúde: uma abordagem estratégica com base em competências. Dissertação (Mestrado Profissional em Saúde Pública) - Programa de Pós-Graduação em Saúde Pública, Escola Nacional de Saúde Pública Sergio Arouca, Fundação Oswaldo Cruz, Rio de Janeiro, 2009.

ASSUNÇÃO, Ada A.; OLIVEIRA, Dalila A. Intensificação do trabalho e saúde dos professores. Educação \& Sociedade, Campinas, v. 30, n. 107, p. 349-372, 2009.

BAUER, Martin W.; GASKELL, George; ALLUM, Nicholas C. Pesquisa qualitativa com texto, imagem e som: um manual prático. 7. ed. Petrópolis: Vozes, 2008.

BEHRING, Elaine R. O Brasil e a mundialização do capital: privatização, deslocalização e flexibilização das relações de trabalho. In: SERRA, Rose (org.). Trabalho e reprodução: enfoques e abordagens. São Paulo: Cortez; Rio de Janeiro: Petres-FSS/Uerj, 2001.

BOSI, Antônio P. A precarização do trabalho docente nas instituições de ensino superior do Brasil nesses últimos 25 anos. Educação \& Sociedade, Campinas, v. 28, n. 101, p. 1.503$-1.523,2007$.

BRASIL. Ministério da Saúde. Secretaria de Gestão do Trabalho e da Educação na Saúde. Gestão do trabalho e da regulação profissional em saúde: agenda positiva do Departamento de Gestão e da Regulação do Trabalho em Saúde. Brasília: Ministério da Saúde, 2005. Disponível em: <http://bvsms.saude.gov.br/ bvs/publicacoes/agenda_positiva.pdf $>$. Acesso em: 19 out. 2016.

BRASIL. Secretaria de Gestão do Trabalho e da Educação na Saúde. Programa Nacional de Desprecarização do Trabalho no SUS. DesprecarizaSUS: perguntas \& respostas. Brasília: Ministério da Saúde, 2006. Disponível em: <http://bvsms.saude.gov.br/bvs/ publicacoes/desprec_cart.pdf $>$. Acesso em: 26 out. 2014.

BRASIL. Portaria n. 1.823/GM, de 23 de agosto de 2012. Institui a Política Nacional de Saúde do Trabalhador e da Trabalhadora. Diário Oficial [da] República Federativa do Brasil, Brasília, DF, 24 ago. 2012. Disponível em: <http://bvsms.saude.gov.br/bvs/saudelegis/ gm/2012/prt1823_23_08_2012.html >.

Acesso em: 19 out. 2016.

CASTEL, Robert. As metamorfoses da questão social: uma crônica do salário. Petrópolis: Vozes, 2003.

COSTA, Daniel O.; TAMBELLINI, Anamaria T. A visibilidade dos escondidos. Physis: Revista de Saúde Coletiva, Rio de Janeiro, v. 19, n. 4, p. 953-968, 2009.

COSTA, Márcia S. O sistema de relações de trabalho no Brasil: alguns traços históricos e sua precarização atual. Revista Brasileira de Ciências Sociais, São Paulo, v. 20, n. 59, p. 111-131, 2005.

DEJOURS, Christophe. A loucura do trabalho. São Paulo: Cortez, 1980. 
DEJOURS, Christophe. Da psicopatologia à psicodinâmica do trabalho. 2. ed. In: LANCMAN, Selma; SZNELMAN, Laerte I. (orgs.). Rio de Janeiro: Editora Fiocruz; Brasília: Paralelo 15, 2008. p. 988-990.

DEJOURS, Christophe; ABDOUCHELI, Elisabeth. Itinerário teórico em psicopatologia do trabalho. In: DÉJOURS, Christophe; ABDOUCHELI, Elisabeth; JAYET, Christian (orgs.). Psicodinâmica do trabalho: contribuições da escola dejouriana à análise da relação prazer, sofrimento e trabalho. São Paulo: Atlas, 2007. p. 125-126.

DRUCK, Graça; FRANCO, Tânia. Trabalho e precarização social. Caderno $C R H$, Salvador, v. 24, n. spe. 1, p. 9-13, 2011.

DURAND, Marc; SAURY, Jacques; VEYRUNES, Philippe. Relações fecundas entre pesquisa e formação docente: elementos para um programa. Cadernos de Pesquisa, São Paulo, v. 35, n. 125, p. 37-62, 2005.

FREITAS, Maria E. O pesquisador hoje: entre $\mathrm{o}$ artesanato intelectual e a produção em série. Cadernos Ebape.br (FGV), Rio de Janeiro, v. 9, p. 1.158-1.163, 2011. Disponível em: $<$ http://bibliotecadigital.fgv.br/ojs/index. php/cadernosebape/article/view/5239/3973>. Acesso em: 19 out. 2016.

FUNDAÇÃO OSWALDO CRUZ (FIOCRUZ). Vice-Presidência de Ensino e Recursos Humanos. Fiocruz: a força do trabalho. Rio de Janeiro: Editora Fiocruz, 2004.

GADELHA, Carlos A. G. O complexo industrial da saúde e a necessidade de um enfoque dinâmico na economia da saúde. Ciência \& Saúde Coletiva, Rio de Janeiro, v. 8, n. 2, p. 521-535, 2003.

GARCIA, Maria M. A.; ANADON, Simone B. Reforma educacional, intensificação e autointensificação do trabalho docente. Educação \& Sociedade, Campinas, v. 30, n. 106, p. 63-85, 2009.

GIANNOTTI, Vito. História das lutas dos trabalhadores no Brasil. Rio de Janeiro: Mauad X, 2007.
GILL, Rosalind. Análise de discurso. In: BAUER, Martin W.; GASKELL, George. Pesquisa qualitativa com texto, imagem e som: um manual prático. 7. ed. Petrópolis: Vozes, 2008. p. 244-270.

GOLDENBERG, Miriam. A arte de pesquisar: como fazer pesquisa qualitativa em ciências sociais. Rio de Janeiro: Record, 2001.

GOMES, Darcilene C.; SILVA, Leonardo B.; SÓRIA, Sidartha. Condições e relações de trabalho no serviço público: o caso do governo Lula. Revista de Sociologia e Política, Curitiba, v. 20, n. 42, p. 167-181, 2012.

GOMEZ, Carlos M.; THEDIM-COSTA, Sonia M. F. Precarização do trabalho e desproteção social: desafios para a saúde coletiva. Cadernos de Saúde Pública, Rio de Janeiro, v. 4, p. 411-421, 1999.

HARVEY, David. O enigma do capital: e as crises do capitalismo. São Paulo: Boitempo, 2011.

JORGE, Maria S. B. et al. Gestão de recursos humanos nos centros de atenção psicossocial no contexto da Política de Desprecarização do Trabalho no Sistema Único de Saúde. Texto \& Contexto Enfermagem, Florianópolis, v. 16, n. 3, p. 417-425, 2007.

LACAZ, Francisco A. C. O campo saúde do trabalhador: resgatando conhecimentos e práticas sobre as relações trabalho-saúde. Cadernos de Saúde Pública, Rio de Janeiro, v. 23, n. 4, p. 757-766, 2007.

LELIS, Isabel. O trabalho docente na escola de massa: desafios e perspectivas. Sociologias, Porto Alegre, v. 14, n. 29, p. 152-174, 2012.

LEMOS, Denise. Trabalho docente nas universidades federais: tensões e contradições. $\mathrm{Ca}$ derno $C R H$, Salvador, v. 24, n. especial 1, p. 105-120, 2011.

MACHADO, Maria H.; KOSTER, Isabella. Emprego e trabalho em saúde no Brasil: as políticas de desprecarização do Sistema Único de Saúde. In: ASSUNÇÃ̃, Ada A.; BRITO, 
Jussara (orgs.). Trabalhar na saúde: experiências cotidianas e desafios para a gestão do trabalho e do emprego. Rio de Janeiro: Editora Fiocruz, 2011. p. 195-213.

MARQUEZE, Elaine C.; MORENO, Claudia R. C. Satisfação no trabalho: uma breve revisão. Revista Brasileira de Saúde Ocupacional, São Paulo, v. 30, n. 112, p. 69-79, 2005.

MAUÉS, Olgaíses C. A reconfiguração do trabalho docente na educação superior. Educar em Revista, Curitiba, n. especial 1, p. 41-160, 2010.

MENDONÇA, André L. O. Dos valores de medida aos valores como medida: uma avaliação axiológica da avaliação acadêmica. Ensaios Filosóficos, Rio de Janeiro, v. 10, p. 111-133, 2014. Disponível em: <www. ensaiosfilosoficos.com.br/Artigos/Artigol0/ MENDONCA_Andre_Da_Bibliometria_a_ Axiologia.pdf>. Acesso em: 19 out. 2016.

MENDONÇA, André L. O.; CAMARGO JR., Kenneth R. Complexo médico-industrial/financeiro: os lados epistemológico e axiológico da balança. Physis: Revista de Saúde Coletiva, Rio de Janeiro, v. 22, n. 1, p. 215238, 2012.

MÉSZÁROS, István. Desemprego e precarização: um grande desafio para a esquerda. In: ANTUNES, Ricardo (org.). Riqueza e miséria do trabalho no Brasil. São Paulo: Boitempo, 2006.

MINAYO, Maria C. S. O desafio do conhecimento: pesquisa qualitativa em saúde. 12. ed. São Paulo: Hucitec, 2010.

MONY, Annie-Thébaut; DRUCK, Graça. Terceirização: a erosão dos direitos dos trabalhadores na França e no Brasil. In: DRUCK, Graça; FRANCO, Tânia (orgs.). A perda da razão social do trabalho: terceirização e precarização. São Paulo: Boitempo, 2007. p. 23-58.

MUROFUSE, Neide T. et al. Diagnóstico da situação dos trabalhadores em saúde e o processo de formação no polo regional de educação permanente em saúde. Revista Latino-Americana de Enfermagem, Ribeirão Preto, v. 17, n. 3, p. 314-320, 2009.

NOGUEIRA, Roberto P. Problemas de gestão e regulação do trabalho no SUS. Rede Observatório de Recursos Humanos. Repertório com a produção da Rede ObservaRH-Brasil. 2006. Disponível em: <www.observarh.org. br/observarh/repertorio/Repertorio_ ObservaRH/NESP-UnB/Problemas_gestao_ regulacao.pdf $>$. Acesso em: 26 out. 2014.

NOGUEIRA, Roberto P.; BARALDI, Solange; RODRIGUES, Valdemar A. Limites críticos das noções de precariedade e desprecarização do trabalho na administração pública. Observatório de Recursos Humanos em Saúde no Brasil: estudos e análises. v. 2. Brasília: UnB, 2005. p. 81-103. Disponível em: <www. obsnetims.org.br/uploaded/24_1_2014_0_ Observatorio_volume_dois.pdf $>$. Acesso em: 19 out. 2016.

ODDONE, Ivar et al. Ambiente de trabalho: a luta dos trabalhadores pela saúde. São Paulo: Hucitec, 1986.

OLIVEIRA, Dalila A. A reestruturação do trabalho docente: precarização e flexibilização. Educação \& Sociedade, Campinas, v. 25, n. 89, p. 1.127-1.144, 2004.

OLIVEIRA, Íris M. S.; GALVÃO, Maria E. M. O compromisso com a legalidade e legitimidade. In: OLIVEIRA, Íris M. S.; GALVÃO, Maria E. M. (orgs.). Gestão pública: uma abordagem dos procedimentos administrativos. Fortaleza: Escola de Saúde Pública do Ceará, 2007. p. 40- 48.

PIERANTONI, Célia R. et al. Gestão do trabalho e da educação em saúde: recursos humanos em duas décadas do SUS. Physis: Revista de Saúde Pública, Rio de Janeiro, v.18, n. 4, p. 685-704, 2008.

RÉZIO, Larissa A.; OLIVEIRA, Alice G. B. Equipes e condições de trabalho nos centros de atenção psicossocial em Mato Grosso. Escola Anna Nery Revista de Enfermagem, Rio de Janeiro, v. 14, n. 2, p. 346-354, 2010. 
SANTOS, Maria A. B.; PASSOS, Sonia R. L. Comércio internacional de serviços e complexo industrial da saúde: implicações para os sistemas nacionais de saúde. Cadernos de Saúde Pública, Rio de Janeiro, v. 26, n. 8, p. 1.483-1.493, 2010 .

SCHWARTZ, Yves; DURRIVE, Louis. Trabalho e ergologia: conversas sobre a atividade humana. Niterói: EdUFF, 2007.

SENNETT, Richard. A corrosão do caráter: consequências pessoais do trabalho no novo capitalismo. Rio de Janeiro: Record, 2002.

SENNETT, Richard. Respeito: a formação do caráter em um mundo desigual. Rio de Janeiro: Record, 2004.
SILVA, Luiz M. O. (Des)estruturação e (des)regulamentação do trabalho: uma análise preliminar dos impactos sobre o setor de saúde. Revista da Fapese de Pesquisa e Extensão, Aracaju, v. 2, p. 85-100, 2006.

SOUZA, Katia R.; ROZEMBERG, Brani. As macropolíticas educacionais e a micropolítica de gestão escolar: repercussões na saúde dos trabalhadores. Educação e Pesquisa, São Paulo, v. 39, n. 2, p. 433-447, 2013.

TURATO, Egberto R. Métodos qualitativos e quantitativos na área da saúde: definições, diferenças e seus objetos de pesquisa. Revista de Saúde Pública, São Paulo, v. 39, n. 3, p. 507-514, 2005.

Recebido em 24/03/2015

Aprovado em 17/08/2016 